\title{
PAIETS: sobre trajetórias e sonhos de um programa de extensão
}

\author{
PAIETS: about trajectories and dreams of an extension program
}

\author{
Roberta Avila Pereira ${ }^{1}$ Lisiane Costa Claro $^{2}$ \\ 1 Mestranda. Universidade Federal do Rio Grande (FURG), Brasil. E-mail: robertapereira108@gmail.com \\ 2 Professora. Doutora. Universidade Federal do Rio Grande (FURG), Brasil. E-mail: lisianecostaclaro@gmail.com
}

Recebido em: 01/03/2020 | Aprovado em: 08/04/2020

DOI: $10.12957 /$ interag.2019.48796

\begin{abstract}
Resumo
O Programa de Auxílio ao Ingresso nos Ensinos Técnico e Superior (PAIETS), vinculado à Universidade Federa do Rio Grande (FURG), é um Programa extensionista de inclusão social que atualmente atua em três instâncias: 1. Auxílio ao Ingresso no Ensino Superior e Técnico; 2. Permanência das Camadas populares e comunidades tradicionais (indígenas e quilombolas) na Universidade; 3. No acesso à Pós-Graduação, através do projeto denominado PAIETS Pós-graduação. O PAIETS vem sendo desenvolvido desde 2007, como programa de extensão. Além disso, é um Programa que envolve vários setores da sociedade civil como movimentos Sociais, Organizações e Coletivos Populares. Da mesma forma, o PAIETS representa um movimento que articula parcerias em instâncias institucionais por meio das escolas da rede pública das regiões que constituem os espaços de atuação do Programa. Neste sentido, inserese no esforço nacional de enfrentamento à exclusão das classes populares ao ensino superior e técnico potencializando seu ingresso nestas instituições. Assim, nas instâncias evidenciadas, almeja-se a democratizaçãc dos espaços formativos institucionalizados por meio de uma postura crítica e emancipadora. Por meio da Educação Popular, o PAIETS auxilia na responsabilidade social assumida com a comunidade.
\end{abstract}

Palavras-chave: Extensão; Educação Popular; Trajetória.

Área temática: Educação.

Linha de extensão: Educação Popular; Trajetória.

\begin{abstract}
The Assistance Program for Admission to Technical and Higher Education (PAIETS), linked to the Federal University of Rio Grande (FURG), is an extension program for social inclusion that currently operates in three instances: 1. Assistance for Admission to Higher and Technical Education ; 2. Permanence of popular layers and traditional communities (indigenous and quilombolas) at the University; 3. When accessing Postgraduate Studies, through a project called PAIETS Postgraduate Studies. PAIETS has been developed since 2007, as an extension program. In addition, it is a Program that involves various sectors of civil society such as Social movements, Organizations and Popular Collectives. Likewise, PAIETS represents a movement that articulates partnerships in institutional instances through public schools in the regions that constitute the areas where the Program operates. In this sense, it is part of the national effort to face the exclusion of popular classes from higher and technical education, enhancing their entry into these institutions. Thus, in the evidenced instances, the aim is to democratize institutionalized training spaces through a critical and emancipatory posture. Through Popular Education, PAIETS assists in social responsibility assumed with the community.
\end{abstract}

Keywords: Extension; Popular Education; Trajectory. 


\section{Primeiras Palavras}

O Programa de Auxílio ao Ingresso ao Ensino Técnico e Superior - PAIETS é um Programa de inclusão social que tem três frentes de atuação: 1) No acesso ao Ensino Superior junto aos Pré-Universitários Populares; 2) Na permanência de sujeitos oriundos de comunidades quilombolas e indígenas no espaço acadêmico; 3) No acesso à pósgraduação. Na primeira frente, o Programa agrupa Cursos Pré-universitários Populares voltados ao ingresso nos ensinos superior e técnico, configurando-se enquanto um movimento articulador entre as comunidades urbanas periféricas por meio da busca ao direito do ingresso das camadas populares nos espaços educativos historicamente destinados às camadas mais abastadas. Nesse processo de luta pelo acesso à Universidade, acadêmicos de graduação, pós-graduação, além de docentes e colaboradores graduados, desenvolvem práticas educativas em diferentes áreas do conhecimento que auxiliam no preparo ao Exame Nacional do Ensino Médio - ENEM.

Encontram-se vinculados ao programa 07 cursos Pré-Universitários Populares no município do Rio Grande/RS, que estão em desenvolvimento nas vilas e bairros populares da cidade, sendo eles: Paideia; Maxximus; Fênix; Acreditar; Quinta Superação; Esperança e Povo Novo. Além disto, 01 curso Pré-Universitário Popular em São José do Norte/RS, Ousadia Popular, 01 curso Pré-Universitário Popular em Capão do Leão/RS, Curso Up e 01 curso Pré-Universitário Popular em Santo Antônio da Patrulha/RS, Super Ação Comunitária (Saci).

Com relação à reivindicação pela permanência dos sujeitos oriundos das comunidades tradicionais indígenas e quilombolas no espaço acadêmico, desde 2012, em coerência com a Lei $\mathrm{n}^{\circ} 12.711 / 2012^{1}$, que trata da Política de Cotas, o PAIETS Indígena e Quilombola surge enquanto uma demanda voltada ao acolhimento e à permanência de estudantes indígenas e quilombolas. Neste sentido, as práticas do Programa visam realizar um acompanhamento desses estudantes por meio de oficinas. Esses encontros emergem a partir da demanda em relação aos desafios enfrentados pelos educandos ao adentrar à 
Universidade, trabalhando a partir das suas necessidades, para uma melhoria no seu desempenho enquanto graduando.

A respeito do acesso à pós-graduação, o PAIETS também promove, a partir da parceria com o Laboratório de Estudos e Pesquisas sobre Identidades, Currículos e Culturas: Nós do Sul, um curso de preparação que visa auxiliar as camadas populares para as etapas do processo seletivo de mestrado e doutorado na área de Ciências Humanas.

Neste rumo, as ações do PAIETS, no que concerne aos pressupostos epistemológicos, apostam na democratização do ingresso e permanência na Universidade como direito, entendendo que através da inserção participativa e crítica de sujeitos, que historicamente estão à margem da sociedade, é que alcançaremos a transformação social que almejamos. Além disso, é um Programa que envolve vários setores da sociedade civil como movimentos sociais, organizações e coletivos populares. Da mesma forma, o PAIETS representa um movimento que articula parcerias em instâncias institucionais por meio das escolas da rede pública das regiões que constituem os espaços de atuação do PAIETS.

Assim, nas três instâncias evidenciadas, almeja-se a democratização dos espaços formativos institucionalizados por meio de uma postura crítica e emancipadora. Por meio da Educação Popular, o PAIETS auxilia na responsabilidade social assumida pela Universidade Federal do Rio Grande - FURG com a comunidade. 


\section{Sobre os caminhos do PAIETS}

Com a forte influência neoliberal que se instaurava no país na década de 90, os movimentos sociais populares, que reivindicavam a ocupação de espaços negligenciados às camadas populares, demonstravam sua resistência frente à lógica que reforçava conceitos como "qualidade e excelência", "produtividade", "sucesso", vinculados a um ideal meritocrático e de cunho opressor, o qual desconsidera os elementos condicionantes de uma sociedade desigual. Neste sentido, a comunidade riograndina, passa a organizar-se em alguns bairros da cidade de maneira a constituir espaços educativos com o objetivo do ingresso à Universidade.

A experiência germinal do PAIETS emerge da organização de cursos préuniversitários populares na cidade do Rio Grande no ano de 2000 com o curso préuniversitário popular "Sem Limites", que mais tarde passou a chamar-se de "Utopia”. Este curso acontecia nas dependências do Hospital Universitário e teve início com a organização autônoma de estudantes vinculados ao movimento estudantil da FURG.

Com o passar dos anos, novas experiências são criadas em diferentes comunidades urbanas periféricas da cidade. Esses cursos tinham como ponto de confluência a busca pelo acesso das camadas populares ao ensino superior. Cumpre registrar que foi um processo que teve como incentivo a experiência que ocorria na cidade vizinha de Rio Grande: o curso pré-vestibular Desafio, o qual era organizado por estudantes da Universidade Federal de Pelotas desde os anos 90. Nesta década surgem diversas experiências que pautam o acesso ao Ensino Superior como uma luta por direitos. E é só no fim dos anos 90 que essas iniciativas conseguem aglutinar esforços conjuntos e produzem então ações reivindicatórias gerais que vão impactar o cenário da Educação após os anos 2000.

No ano de 2006, surge um projeto de extensão que procurava articular essas iniciativas. Foi uma conquista para a organização dessas experiências, sendo uma realização importante que serviria de base para o fortalecimento da luta pelo ingresso na 
Universidade. A partir do ano de 2007 é aprovado o PAIETS no âmbito da FURG, enquanto um Programa de Extensão contemplado no edital PROEXT 06/2007, visando contribuir na criação e manutenção dos diversos cursos voltados à luta de ingresso da comunidade popular ao ensino técnico e superior públicos.

O PAIETS buscava congregar estas experiências no horizonte da Educação Popular, objetivando a partilha das conquistas e dos desafios presentes nos diferentes contextos. Sobretudo, a proposta tinha como intuito fortalecer as experiências na luta pelo acesso à universidade, mantendo e respeitando a autonomia de cada um dos cursos os quais funcionavam em parceria com a comunidade geral.

Desta forma, o Programa já atuou em outras instâncias, para além das já citadas: a) $\mathrm{Na}$ retomada à educação básica junto a Jovens e Adultos (das comunidades tradicionais de pesca artesanal e da comunidade LGBT, nas quais o PAIETS surge como parceiro de organização); b) Na formação docente da rede pública junto a Educação de Jovens e Adultos - EJA; c) No diálogo intercultural junto aos imigrantes senegalês em Rio Grande/RS.

Neste sentido, como a primeira frente de luta, o PAIETS agrupou e ainda reúne cursos Pré-Universitários Populares e Pré-IF (Institutos Federais, com o foco no ensino médio técnico), configurando-se enquanto um movimento articulador entre as comunidades urbanas periféricas, e um curso na zona rural numa comunidade de pesca artesanal, por meio da busca ao direito do ingresso das camadas populares nos espaços de privilégio.

Atualmente, além do acesso aos cursos técnicos e de graduação, o PAIETS também contribui para o ingresso nos programas de pós-graduação da universidade pública. Cabe ressaltar o contexto Cultura da Paz que atuou em 2016 e 2017 com pessoas em privação de liberdade; foi um ambiente educativo que visava à reinserção social e ao ingresso na universidade, no horizonte da justiça restaurativa. Destaca-se, também, o Pré- 
Universitário Educação para Pescadores, que foi um desdobramento da experiência junto ao projeto Educação para Pescadores na modalidade EJA.

Neste sentido, sobre esta experiência mencionada de retomada pelo acesso ao ensino básico, o PAIETS promoveu, com a colaboração de parcerias das secretarias municipais e estaduais, práticas educativas em zonas periurbanas e rurais com o Ensino de Jovens e Adultos de comunidades de pesca artesanal. Além disso, o projeto Manas na Escola, realizado junto a demanda da comunidade LGBT, por meio da Associação LGBT de Rio Grande em parceria com a Prefeitura, buscou um espaço de compartilhamento de saberes com o foco em travestis e transexuais do gênero feminino, tendo em vista a grande evasão da escola devido às dificuldades e preconceitos sociais.

O Programa junto ao Curso Educação de Jovens e Adultos na Diversidade e Inclusão Social ofertou a formação, em nível de aperfeiçoamento, no espaço de formação permanente com educadores da EJA da rede pública municipal e estadual de Rio Grande, São Lourenço do Sul e Capão do Leão. Trata-se de um curso voltado à formação continuada de educadores da EJA, onde eram realizados encontros em círculos de cultura. A metodologia orientadora dos encontros com os participantes vinculados ao projeto, divididos em pequenos grupos, partiu da compreensão que a prática educativa precisa ser repensada e ressignificada.

Uma outra frente de atuação de extensão vinculada ao programa foi o PAIETS Imigrantes: diálogos interculturais que buscaram estabelecer um diálogo com os imigrantes senegaleses em Rio Grande/RS. Através do reconhecimento da presença destes imigrantes no município, objetivou-se o reconhecimento das manifestações culturais e possibilidades de aprendizagens outras, através da escutatória freireana (compreendemos que o termo "escutatória" provoca um alargamento de sentido e preconiza uma outra possibilidade de interação, por meio de uma escuta ativa e de abertura ao diálogo com o outro de maneira mais sensível e humana, no horizonte freireano. É um espaço onde se busca alcançar outras formas de intercâmbios de vivências e aprendizagens). Com efeito, nesta frente de luta do programa, foi reafirmada a 
importância destes imigrantes e suas dimensões de vida como aprendizagens no horizonte da Educação Popular.

Atualmente, o PAIETS está desenhado pela busca do acesso ao ensino superior, tanto na graduação, quanto pós-graduação; no ingresso ao Ensino Técnico de Nível Médio no âmbito Público. Também continua atuando na permanência no Ensino Superior, por meio do PAIETS Indígena e Quilombola.

As vivências que emergem neste percurso de Programa são indispensáveis para a compreensão do alcance que o trabalho coletivo tem junto à comunidade. O PAIETS identifica sua consolidação e pertinência na luta por uma Universidade mais justa e democrática, bem como na construção de uma sociedade mais humana e igualitária, ao reconhecer as histórias de vida dos sujeitos que contribuem para sua (re)existência.

As contribuições para a instituição e para a sociedade estão embasadas na possibilidade de formação crítica dos sujeitos das camadas populares que estudam nos contextos de atuação do PAIETS, bem como demonstram a aproximação do espaço acadêmico a esta população que ainda não ingressou no Ensino Superior. Assim, as contribuições emergem ao salientarmos a pertinência de uma prática ética e responsável nas comunidades populares nas quais o Programa está inserido e a postura comprometida nestas ações traduz a responsabilidade social da Universidade.

Nesse sentido, são organizados, ao longo do ano letivo, encontros formativos, tais como: Aula Inaugural do PAIETS; Encontro de Formação de Educadores; Feira das Profissões; Aulão de Dicas para o ENEM. Estas atividades emergem a partir da necessidade da formação permanente e qualificada nos contextos educativos, de modo que o PAIETS tem uma proposta político-pedagógica bem definida. As ações se fortalecem na medida em que são promovidos encontros de formação coletiva, unificando educadores e garantindo a unidade do horizonte epistemológico, na diversidade de ações e contextos. 
Além do ingresso e permanência das camadas populares na Universidade, compreendemos que a entrada destes sujeitos representa a ampliação da luta pela justiça social. Os cursos trabalham em favor da luta dos oprimidos, sendo a formação humana presente em cada contexto, o diferencial que nutre as expectativas de um projeto de sociedade menos desigual.

\section{A luta pelo acesso à educação}

$\mathrm{Na}$ atual estrutura de nossa sociedade, são notórias as contradições da lógica capitalista existentes no processo educativo, principalmente no que concerne à luta cotidiana da camada popular para ter acesso, permanecer na Universidade e concluir seus estudos. A lógica do capital promove a necessidade de os sujeitos ingressarem cedo no mercado de trabalho e, desse modo, é impossibilitada a continuidade de escolarização de muitos sujeitos,

Nesse contexto de desigualdade social que permeia a educação, é possível entender que a classe opressora foi quem induziu muitos dos sujeitos das classes populares a permanecerem fora dos processos educativos formais e, consequentemente, não tivessem a oportunidade de acesso e permanência nas instituições de ensino. Tendo em vista as dificuldades de adequação ao sistema educativo capitalista, jovens e adultos tiveram seus direitos negligenciados e foram marginalizados, servindo ao sistema como mão de obra de forma alienada.

A educação hoje é utilizada na formação de jovens para o mercado de trabalho e o ensino visa uma instrução que atenda as demandas mercadológicas. Isso nos leva a refletir também a respeito de quão alta é a assimetria entre o capital e o trabalho, pois temos o desemprego por falta de mão de obra de um lado e, no outro, oferta de empregos árduos, com salários baixíssimos.

Tal situação ocasiona nas escolas públicas de ensino médio e fundamental, a desesperança dos professores com as possibilidades de alteração deste quadro, e 
consequentemente, nas possibilidades de acesso de seus educandos ao Ensino Superior. Como decorrência desses fatores é que o PAIETS se apresenta como proposta de Educação Popular emancipadora de sujeitos que vivem em condições menos favorecidas.

Portanto, os cursos pré-universitários populares estão para além de uma preparação para os processos seletivos, pois auxiliam na consolidação de uma educação crítica que reivindica um caminho para a construção de uma Universidade inclusiva, através do diálogo com os diferentes grupos sociais que constituem as camadas populares ${ }^{2}$.

Cabe destacar que a perspectiva de Educação Popular parte da construção junto às camadas populares, a partir de seu contexto com o propósito de transformação política e social, tendo como foco a disputa pelo exercício à cidadania. Neste sentido, "A Educação Popular, postula, então, o esforço de mobilizar e organizar as classes populares com o objetivo de conceber um poder popular". ${ }^{3}$ Assim, a Educação Popular compreende intencionalidade emancipatória e esta emancipação ocorre por meio do diálogo que conduz os sujeitos à visão crítica acerca das relações sociais de produção que perpetuam discursos e práticas, as quais tendem a homogeneizar os educandos.

Carlos Brandão ${ }^{4}$ compreende e sugere que "A Educação Popular não é uma atividade pedagógica para, mas um trabalho coletivo em si mesmo”. E, neste sentido, está intrínseca a aposta nos sujeitos enquanto protagonistas de suas histórias, que buscam em suas lutas cotidianas superar a lógica de um sistema que não acredita nas condições de emancipação do sujeito. E uma destas lutas é a concretização da esperança de ingressar no Ensino Superior, entendendo-o como um dos espaços de direito e possível de ser trilhado. A Educação Popular desenvolvida pelo PAIETS deve ser compreendida a partir de uma Pedagogia libertadora no sentido freireano. ${ }^{5}$

Nesse horizonte, considera-se que a educação não deve estar limitada ao caráter científico de maneira a negar os conhecimentos oriundos das vivências e contextos dos 
sujeitos. Essa busca pelo respeito e valorização das culturas representa a utopia motivadora de nossa ação na esfera da educação. Nesse prisma,

[...] educação a percebemos como interlocução de saberes sempre em reconstrução através das aprendizagens no mundo das vivências dos sujeitos singularizados, vivências que se ressignificam nos espaços e tempos sociais dos distintos âmbitos linguísticos e do convívio das alteridades distintas. ${ }^{6}$

Com essa ideia de construção dos saberes, é fundamental conhecer e disseminarmos possibilidades que estimulem práticas educativas as quais valorizem os educandos e suas experiências de vida. Ainda nesse horizonte, Paulo Freire e Antônio Faundez7 apontam a necessidade de a educação apropriar-se dos sentimentos (oriundos da comunidade), não se detendo assim apenas na racionalidade do que é científico.

Zitkoski $^{8}$ aponta que a Educação Popular assume sua importância, na medida em que promove a resistência contra opressão e exploração, levando ao processo de libertação das camadas populares. Neste sentido, é preciso que esta educação esteja comprometida com uma prática político-educativa intencional e planejada, uma vez que "o sentido e a coerência política do trabalho concreto da Educação Popular está na radicalidade da proposta de transformação social."

Pondera-se que a Educação Popular, ontologicamente, deve movimentar-se contra as desigualdades, compreendendo e problematizando as contradições impostas, buscando a libertação com o coletivo, a conscientização do povo, rompendo com a condição que sustenta a camada opressora. Por isso, compreende-se que a postura exigida nas práticas pedagógicas no pré-universitário precisa estar voltada para a criticidade dos educandos e educandas, através de formação continuada e permanente. Precisa-se estabelecer uma relação de confiabilidade que aponta para uma nova ontologia, criando possibilidades dos sujeitos de "ser mais". 
O processo de aprendizagem está profundamente relacionado ao processo de conscientização, compreendendo que o processo de conhecimento, a partir da lógica da própria cultura, do ponto de vista pedagógico, é mais importante que o produto deste conhecimento. Por isso, o ponto de partida do ato educativo é o mundo vivido e experienciado, mas não apenas para redizê-lo, mas para superá-lo através dele. Nesse sentido, Freire ${ }^{3}$ afirma que a partir dos saberes da vida dos sujeitos, é que desenvolveremos práticas emancipatórias e coletivas o que significa propor um novo olhar sobre questões que estão no âmbito educativo.

\section{Considerações finais}

O PAIETS tem na extensão universitária a possibilidade de reivindicar não só uma academia mais democrática e popular, como um mundo mais igualitário. Contudo, a caminhada só é possível junto aos sujeitos que atuam no horizonte da superação dos limites impostos frente ao modelo hegemônico. Estes protagonistas partem da comunidade geral que acolhe os contextos de atuação do Programa, as escolas públicas que sediam os cursos, os educandos que acreditam no trabalho realizado e que participam da construção destes espaços, os educadores populares que não carregam um frágil sentido de voluntarismo, mas compreendem-se enquanto indivíduos dispostos a aprender com o outro na luta pela defesa à educação de todas as pessoas.

Compreendemos que a entrada das camadas populares na Universidade representa a ampliação da luta pela justiça social. Os contextos trabalham em favor da luta dos oprimidos; sendo a formação humana presente em cada contexto, o diferencial que nutre as expectativas de um projeto de sociedade menos desigual. É possível afirmar que a maioria dos egressos do Programa são indivíduos conscientes de sua responsabilidade social no contraponto à lógica opressora.

Lideranças, representantes de movimentos sociais estudantis e demais movimentos populares, profissionais comprometidos com os aspectos da comunidade, são sujeitos que se formam nos contextos do PAIETS. Assim, é preciso destacar que o 
Programa é nutrido pelos sonhos dos inconformados com as desigualdades e com as opressões, que ao buscarem uma sociedade mais justa por meio da garantia dos direitos conquistados pelo povo, acreditam e trabalham em favor da humanização e transformação social.

\section{Referências}

1. BRASIL. Lei $\mathrm{N}^{\circ}$ 12.711, de 29 de agosto de 2012. Dispõe sobre o ingresso nas universidades federais e nas instituições federais de ensino técnico de nível médio e dá outras providências. Disponível em: http://www.planalto.gov.br/ccivil_03/_Ato20112014/2012/Lei/L12711.htm. Acesso em: outubro de 2019.

2. THUM, Carmo. Pré-vestibular público e gratuito: o acesso de trabalhadores à universidade pública. 185 f. Dissertação (Mestrado em Educação) - Centro de Ciências da Educação da Universidade Federal de Santa Catarina, Florianópolis. 2000.

3. FREIRE, Paulo. Pedagogia da Autonomia: Saberes necessários á pratica educativa. São Paulo: Paz e Terra. 1996. p. 51.

4. BRANDÃO, Carlos Rodrigues. O que é Educação Popular. São Paulo: Coleção 318, Primeiros Passos, Brasiliense. 2006. p. 89.

5. PEREIRA, Vilmar Alves; GONÇALVES, Leonardo Dorneles. Educação Popular no Contexto do PAIETS - FURG: Os saberes da pesquisa em extensão universitária. Evangraf, Porto Alegre/FURG, 2012.

6. MARQUES, Mário Osório. Educação das ciências: interlocução e complementaridade. Ijuí: Editora Unijuí, 2002. p. 19.

7. FREIRE, Paulo; FAUNDEZ, Antônio. Por uma pedagogia da pergunta. Rio de Janeiro: Paz e Terra, 1985.

8. ZITKOSKI, Jaime José. Educação Popular e Movimentos Sociais na América Latina. In: Anped Sul 2010, 2010, Londrina- PR. VIII Encontro de Pesquisa em Educação da Região Sul - Anped Sul. Londrina-PR: Universidade Estadual de Londrina, 2010. p. 0117 . 